\title{
Effects of Physical Activity Levels on Fatigue Perception in Patients with Parkinson's Disease and Neurologically Healthy Individuals
}

\author{
Paulo Cezar Rocha dos Santos ${ }^{*}$, Fabio Augusto Barbieri, ${ }^{1,2}$, Diego Orcioli-Silva ${ }^{1}$, \\ Lucas Simieli1 ${ }^{1}$ Lilian Teresa Bucken Gobbi ${ }^{1}$ \\ ${ }^{1}$ UNESP, Univ Estadual Paulista at Rio Claro, Rio Claro/SP, Brazil \\ ${ }^{2}$ UNESP, Univ Estadual Paulista at Bauru, Bauru/SP, Brazil \\ Email: paulocezarr@hotmail.com
}

Received 29 August 2014; revised 17 October 2014; accepted 2 November 2014

Copyright (C) 2014 by authors and Scientific Research Publishing Inc.

This work is licensed under the Creative Commons Attribution International License (CC BY). http://creativecommons.org/licenses/by/4.0/

(c) (i) Open Access

\begin{abstract}
Background: Recent researches involving fatigue and Parkinson's disease (PD) sought to verify its incidence and the impacts of fatigue on quality life of patients with PD. Despite the importance of regular physical activity practice, there are only few studies that verified the influence of the levels of physical activity on fatigue in patients with PD. Objective: The aim of this study was to compare perception of fatigue between individuals with PD and neurologically healthy individuals (control group), considering the physical activity levels; and to verify the relation between physical activity levels and fatigue dimensions for individuals with PD and control group. Methods: Eighty individuals (40 patients with PD and 40 control individuals) participated in this study. Physical activity levels were evaluated through Modified Baecke Questionnaire for Older Adults. Multidimensional Fatigue Inventory (MFI) was used in order to evaluate fatigue dimensions (general, physical and mental fatigue, reduced motivation and activity). MANOVA two-way and Pearson linear correlation test were performed to analyze the data. Results: Patients with PD presented higher levels of fatigue, in all dimensions evaluated by MFI, comparing to control individuals. There was no association between physical activity levels and perception of fatigue for patients with PD and control individuals. Conclusion: Patients with PD showed increased perception of fatigue when compared to control individuals, due to PD characteristics. In addition, the perception of fatigue's symptom was not influenced and had no relation by the level of physical activity.
\end{abstract}

\footnotetext{
${ }^{*}$ Corresponding author.
}

How to cite this paper: Santos, P.C.R., Barbieri, F.A., Orcioli-Silva, D., Simieli, L. and Gobbi, L.T.B. (2014) Effects of Physical Activity Levels on Fatigue Perception in Patients with Parkinson's Disease and Neurologically Healthy Individuals. Health, 6, 2927-2933. http://dx.doi.org/10.4236/health.2014.621331 
Keywords

Parkinson's Disease, Symptom of Fatigue, Physical Activity Levels, Non-Motor Symptom

\section{Introduction}

Fatigue is one of the most common non-motor manifestations in patients with Parkinson's disease (PD) [1]-[4]. Fatigue is multifactorial and has been set as a general sense of tiredness or difficulties in starting an activity on the physical or mental sector experienced by an individual during many days or weeks [5]. Nearly $58 \%$ of patients with PD present fatigue [2] [6], with higher incidence in advanced stages of PD [7]. Fatigue is linked with serotonergic dysfunction in basal ganglia and limbic circuits [8] [9], and in thalamus, additional cortical and striatal regions [10]. The exacerbated fatigue may lead the patient to have difficulties in starting and/or completing activities related to carrying weight, manual work, running, walking [4] [5], higher risk of falls [11] and deficits of attention and action planning [4] [5], worsening the quality of life of individuals with PD [12].

Patients with PD have shown higher levels of fatigue than neurologically healthy individuals [13]. Lou and colleagues [4] characterized fatigue in patients with PD, which showed higher levels of fatigue in patients with PD in all dimensions (general, physical and mental fatigue, reduced motivation and activity). Physical activity is an important therapy for PD, increasing dopamine [14] [15] and serotonergic levels [16] [17], which, consequently, may improve the exacerbated physical fatigue. However, only two previous studies [18] [19] considered the effects of physical activity levels on fatigue in individuals with PD so far, which showed contradictory findings. Hoff and colleagues [18] did not find association between physical activity levels and fatigue. On the other hand, Elber and colleagues [19] verified an inverse relationship between perception of fatigue and dynamic physical activity in patients with PD. Therefore, the previous studies [18] [19] did not consider a group of neurologically healthy individuals (control group) for comparison, having an incomplete understanding of effects of physical activity levels on fatigue in individuals with PD.

In order to elucidate this lack in literature, the aim of this study was: 1) to compare perception of fatigue between individuals with PD and neurologically healthy individuals (control group), considering physical activity levels; 2) to verify the association between physical activity levels and fatigue dimensions in individuals with PD and control group. The hypothesis of this study is that individuals with PD present higher perception of fatigue than control group. Besides, it expected that physical activity levels are an intervening factor, where physically active individuals presented lower perception of fatigue than physically inactive individuals, causing interaction between physical activity levels and group. Finally, it was expected that physical activity levels have inverse relationship with fatigue dimensions for both groups.

\section{Materials and Methods}

\subsection{Participants}

One hundred and five individuals participated on this study. But, according to the level of physical activity and exclusion criteria, only 80 individuals were selected. Within these participants, 40 were patients with idiopathic PD (PD group) that were recruited from database of a Program of Physical Activity for patients with Parkinson's Disease (PROPARKI-UNESP at Rio Claro), and 40 were neurologically healthy individuals (control group) recruited from the community. In order to confirm diagnosis, patients were evaluated by a neuropsychiatric based on the defined UK Brain Bank Criteria [20]. For each group, selected participants were distributed into physically active $(n=20)$ and physically inactive $(n=20)$ subjects according to their levels of physical activity.

The exclusion criteria of this study were: 1) for both groups: cognitive impairment which could interfere in the interpretation of the questions of the questionnaire; 2) for patients with PD: diagnosis over stage 3 in the Hoehn and Yahr Scale (H\&Y) [21] [22], inconclusive diagnosis of PD and/or Secondary Parkinsonism Syndrome and/or medication intake.

\subsection{Experimental Design}

Each participant was informed about the procedures and aims of this study, and all individuals signed the con- 
sent term, approved by Ethical Committee local (Protocol \#3083).

Participants of this study were evaluated by a neuropsychiatric in order to verify if they met exclusion criteria. Afterwards, the neuropsychiatric verified the stage of PD through H\&Y scale, disease severity through Unified Parkinson's Disease Rating Scale (UPDRS) [23], and cognitive condition through Mini Mental State Examination (MMSE) [24].

\subsubsection{Determination of Levels of Physical Activity and Perception of Fatigue}

Physical activity levels of each participant were defined by Modified Baecke Questionnaire for Older Adults [25]. This questionnaire evaluates the physical activity levels considering household activities, sports, and leisure time activities. Sports and leisure time activities are calculated through timing intensity, frequency of hours a week and number of months in the previous year according to the table suggested by Bink, Bonjer and Van Der Sluys [26]. The sum of scores from each section reveals the total score of the questionnaire, taking into account that high scores mean high physical activity level. To join the physically active group, independently of presence or not of PD, participant should present scores higher than five in the questionnaire and, for the physically inactive group, the participant should present scores less than four [27] and not having practiced regular and systematized physical activity in the last 3 months.

With the purpose of verifying the perception of fatigue, it was used Multidimensional Fatigue Inventory (MFI) [28]. This questionnaire allows us to measure the perception of fatigue in different populations and has being very used for individuals with PD [29]. MFI measures the subjective perception of fatigue, independently, on general fatigue, physical fatigue, reduced motivation, mental fatigue, and reduced activity dimensions. There are four statements for each dimension, and each one of them presents scores in Lickert scale corresponding from 1 (without fatigue) to 5 (highly fatigued). Therefore, higher scores in the questionnaire mean higher subjective perception of the individual (20-lowest fatigue perception, and 100-highest fatigue perception).

\subsection{Data Analysis}

The dependent variables of interest were statistically analyzed on SPSS 18.0 for Windows ${ }^{\circledR}(\mathrm{p} \leq 0.05)$. Firstly, a descriptive statistical analysis was made for data analysis of normality and homogeneity, through Shapiro-Wilk and Levene tests, respectively. In order to compare physically active and physically inactive individuals with PD for the specific variables of PD (UPDRS, H\&Y scale and MMSE), it was applied ANOVA one-way with factor for levels of physical activity. In order to compare fatigue dimensions between PD and control groups, we used two-way MANOVA, with factor for group and physical activity levels. In order to verify the association between physical activity levels and fatigue dimensions for each group we used the Pearson correlation coefficient.

\section{Results}

For age, there was no difference between the groups (PD and Control) and subgroups (active and inactive). For the score of Beacke questionnaire, ANOVA showed that active PD and Control subjects were different than inactive individuals of both of groups. For clinical variables, physically active group and physically inactive group showed no differences (Table 1).

With respect to the evaluated dimensions through MFI, MANOVA presented group effect (Wilks Lambda $=$ $0.60 ; \mathrm{F}_{3.76}=5.00 ; \mathrm{p}<0.001$ ), but no effect for physical activity levels (Wilks Lambda $=0.90 ; \mathrm{F}_{3.76}=0.87 ; \mathrm{p}=$ 0.393 ) and interaction between factores (Wilks Lambda $=0.79 ; \mathrm{F}_{3.76}=0.20 ; \mathrm{p}=0.81$ ). For group (Figure 1), univariate analysis indicated higher perception of fatigue for PD group in all dimensions: general fatigue $\left(\mathrm{F}_{1.79}=\right.$ 22.97, $\mathrm{p}<0.001)$, physical fatigue $\left(\mathrm{F}_{1.79}=24.57, \mathrm{p}<0.001\right)$, reduced activity $\left(\mathrm{F}_{1.79}=26.21, \mathrm{p}<0.001\right)$, mental fatigue $\left(\mathrm{F}_{1.79}=8.85, \mathrm{p}=0.005\right)$, and reduced motivation $\left(\mathrm{F}_{1.79}=9.53, \mathrm{p}=0.003\right)$, besides total score $\left(\mathrm{F}_{1.79}=9.30, \mathrm{p}\right.$ $<0.001$ ) when compared to control group.

For both control and PD group, Pearson correlation analysis did not show association between scores of Baecke questionnaire and perception of fatigue, either independently on dimensions and MFI total value (Table 2).

\section{Discussion}

The hypothesis of this study was partially confirmed by our findings. Patients with PD showed higher subjective perception of fatigue for all dimensions evaluated by MFI when compared to neurologically healthy elderly. 
Table 1. Means and standard deviations of age, Level of Physical Activity (LPA) and clinical characteristics of Active and Inactive Parkinson's and Control Groups. ${ }^{*}$ Difference $(\mathrm{p}<0.05)$ between active and inactive.

\begin{tabular}{|c|c|c|c|c|}
\hline \multicolumn{5}{|c|}{ Age and Level of Physical Activity } \\
\hline & \multicolumn{2}{|c|}{ Parkinson's Group } & \multicolumn{2}{|c|}{ Control Group } \\
\hline & Active & Inactive & Active & Inactive \\
\hline Age (years) & $70.35 \pm 13.58$ & $68.35 \pm 8.04$ & $66.97 \pm 9.87$ & $65.70 \pm 11.00$ \\
\hline LPA (score) & $7.34 \pm 2.53^{*}$ & $2.76 \pm 1.18^{*}$ & $9.23 \pm 5.04^{*}$ & $2.02 \pm 0.92^{*}$ \\
\hline \multicolumn{5}{|c|}{ Clinical Characteristics } \\
\hline H\&Y (stage) & $1.45 \pm 0.37^{*}$ & $1.70 \pm 0.41^{*}$ & - & - \\
\hline UPDRS activities of daily living (score) & $3.15 \pm 1.98$ & $3.55 \pm 1.79$ & - & - \\
\hline UPDRS motor (score) & $18.75 \pm 7.15$ & $20.85 \pm 6.19$ & - & - \\
\hline MEEM (score) & $28.80 \pm 1.57$ & $28.40 \pm 1.42$ & - & - \\
\hline
\end{tabular}
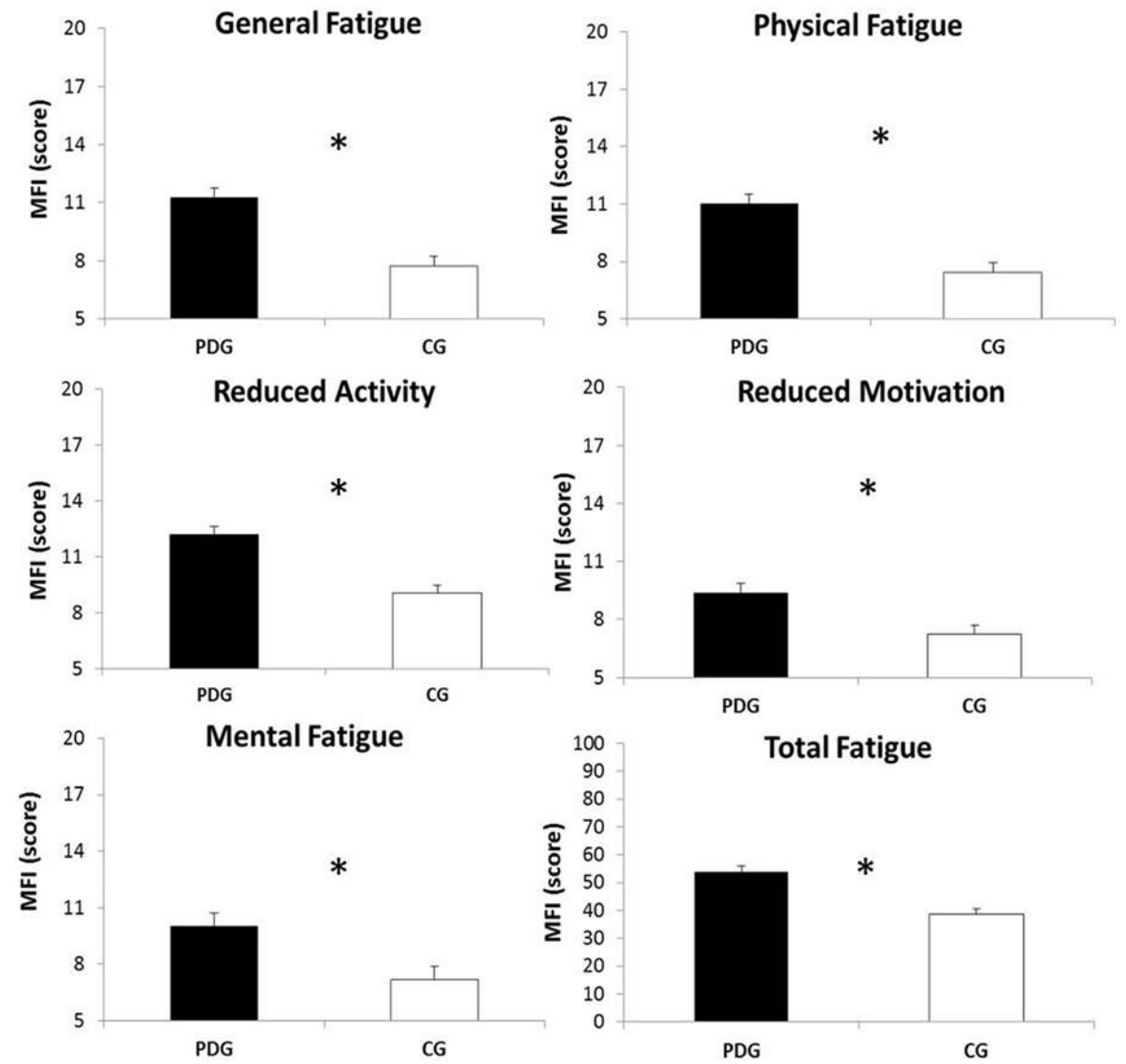

Figure 1. Means and standard deviations of the score on general fatigue, physical fatigue, reduced motivation, mental fatigue, reduced activity dimensions and total score of Multidimensional Fatigue Inventory (MFI) for the Parkinson’s disease (PDG) and Control Groups (CG). *Significant difference $\mathrm{p}<0.001$.

However, there was no effect of physical activity levels on perception of fatigue. Unexpectedly, the results did not show main effect of physical activity levels, group and physical activity levels interaction and correlation between physical active levels and fatigue dimensions. This finding seems to indicate that although the importance of the physical active levels, the perception of fatigue does not appears to be sensitive for physical activity. This will be discussed in details at the next paragraphs. 
Table 2. Person correlation coefficient between the obtained score at the Modified Baecke Questionnaire for Older Adults (MBQO) and the scores on general fatigue, physical fatigue, reduced motivation, mental fatigue, reduced activity dimensions and total score of Multidimensional Fatigue Inventory for the Control and Parkinson's Groups.

\begin{tabular}{rcccccccc}
\hline \multicolumn{7}{c}{ Correlation-Control Group } \\
\hline & & General Fatigue & Physical Fatigue & Reduced Activity & Reduced Motivation & Mental Fatigue & Total \\
\hline $\begin{array}{l}\text { MBQO } \\
\text { (score) }\end{array}$ & Correlation & -0.05 & -0.06 & -0.06 & 0.28 & 0.13 & 0.09 \\
\hline & p-value & 0.38 & 0.35 & 0.36 & 0.09 & 0.21 & 0.29 \\
\hline \multirow{2}{*}{$\begin{array}{l}\text { MBQO } \\
\text { (score) }\end{array}$} & Correlation & -0.05 & Correlation-Parkinson's Group & -0.17 & -0.17 & -0.02 & -0.08 \\
\hline
\end{tabular}

PD causes in higher sense of fatigue. Patients with PD reported higher perception of fatigue, which agrees with literature [4] [13]. This may be explained by the fact that perception of fatigue is related to involvement in the basal ganglia and limbic structures [8] [9], thalamus, striatum and additional cortical region [10], precisely on regions, which are damaged in patients. Thus, PD seems to be an intervenient factor in all fatigue dimensions. Patients presented exacerbated fatigue on general fatigue, physical fatigue, reduced motivation, mental fatigue, and reduced activity dimensions. Regarding physical fatigue dimension, fatigue has been related to functionality, influencing movement speed [30] and increasing risk of falls [11]. On the other hand, the highest values for patients on mental fatigue dimension may be related to problems as depression, reduced motivation, sleeping disorders [4] and decrease on cognitive functions, bringing up losses for actions planning [4] [5]. In this same context, regardless of whether physical or mental characteristic, this screen of fatigue causes great impact on quality of life [6] [12].

Physical activity levels were not an intervenient factor on perception of fatigue. This affirmative corroborates with Hoff and colleagues findings [18] and opposes Elbers and colleagues [19] findings, whose work says that besides finding inverse relationship between physical activity and fatigue, this relation was weak $\left(\mathrm{R}^{2}=20 \%\right)$. This contrary finding may be explained by two factors: 1) different method used to measure physical activity levels_Elber and colleagues [19] and Hoff and colleagues [18] used physical activity monitors, with difference related to the way of monitoring, 8 hours and 6 days, respectively. However, this study used Baecke questionnaire, which despite to be a common tool often used, it is a subjective analysis, and, specifically in this case, with a difficulty in accurately monitoring physical activity frequency; 2) differences in samples characteristicsthe present study did not include patient on stage 4 of H\&Y scale, whereas among patients evaluated by Elbers and colleagues [19], 12\% were on stage 4 . This characteristic might have been a differential factor among studies, and, therefore, may have directly influenced on differences among results obtained by Elber and colleagues [19] and results evidenced in the present work and in the study of Hoff and colleagues [18]. In addition, the use of a physical activity monitor for a period (6 days) seems to present similarity with Baecke questionnaire, that even subjectively, quantifies physical activity practice in the previous year, representing a bigger routine of frequent physical activity practice of evaluated participants.

There was no interaction between physical activity levels and perception of fatigue for both groups. Thus, physical activity levels did not modify perception of fatigue, either in patients with mild-to-moderate PD and in neurologically healthy elderly. This indicates that aging can result in bigger effect on perception of fatigue than physical activity levels on these populations. Therefore, factors related to senescence and others, which were not focus of analysis for this study as depression and anxiety symptoms, may lead to strong effect of aging hiding the effect of physical activity levels. Relating to PD, depression and anxiety factors [1], such as serotonergic dysfunction [10] and sleeping disorders [11] have been associated to perception of fatigue. Despite corroborating with Hoff and colleagues [18] findings, the presence of a control group in this study opposes to the findings of authors when trying to explain why there was no relation between physical activity levels and perception of fatigue. Authors justify why there was no effect of physical activity levels on fatigue by explaining that it may be caused due to factors as PD severity and medication intake. The absence of effects of physical activity levels, also for control groups, blocks factors associated only to characteristics of PD. Regardless of that, the matter that there was no relation between levels of physical activity and fatigue perception eliminates a factor that could interact on fatigue treatment in patients with mild-to-moderate PD. 
Despite important results, limitations related to Baecke questionnaire and MFI are evidenced in the present study. Although Baecke questionnaire is capable of differentiating physically active from physically inactive groups and to have easy access and use, it has some limitations as no quantification of activities involving the work in non-domestic environment. Elderly population has shown a current tendency to be active in work environment, which may oppose to effects of aging and disease, presenting functional and cognitive maintenance, which can represent gains in neuroplasticity [31]. Related to MFI, difficulty of interpreting questions, due to questions similarities that compound dimensions (general fatigue, physical fatigue, reduced motivation, mental fatigue, and reduced activity) from the questionnaire, may have been a discomfort factor for participants.

\section{Conclusion}

From the results, we can conclude that patients with PD present a more pronounced perception of fatigue on general fatigue, reduced motivation, physical fatigue and mental fatigue dimensions, when compared to neurologically healthy individuals. Besides, physical activity levels did not show effect on perception of fatigue in patients with PD and neurologically healthy individuals.

\section{Acknowledgements}

The authors thank FAPESP and CAPES for the financial support.

\section{Conflict of Interest}

The authors have no conflict of interest to report.

\section{References}

[1] Friedman, J.H., Garber, C.E., Krupp, L.P., Lou, J.S.N., Marsh, L., Nail, L., Shulman, L. and Taylor, C.B. (2007) Fatigue in Parkinson's Disease: A Review. Movement Disorders, 22, 297-308. http://dx.doi.org/10.1002/mds.21240

[2] Herlofson, K. and Larsen, J.P. (2003) The Influence of Fatigue on Health-Related Quality of Life in Patients with Parkinson's Disease. Acta Neurologica Scandinavica, 107, 1-6. http://dx.doi.org/10.1034/j.1600-0404.2003.02033.x

[3] Friedman, J.H. and Friedman, H. (2001) Fatigue in Parkinson's Disease. Movement Disorders, 16, 1120-1122. http://dx.doi.org/10.1002/mds.1201

[4] Lou, J.S., Kearns, G., Oken, B., Sexton, G. and Nutt, J. (2001) Exacerbated Physical Fatigue and Mental Fatigue in Parkinson's Disease. Movement Disorders, 16, 190-196. http://dx.doi.org/10.1002/mds.1042

[5] Lou, J.S. (2009) Physical and Mental Fatigue in Parkinson’s Disease: Epidemiology, Pathophysiology and Treatment. Drugs Aging, 26, 195-208. http://dx.doi.org/10.2165/00002512-200926030-00002

[6] Barone, P., Antonini, A., Colosimo, C., Marconi, R., Morgante, L., Avarello, T.P., Bottachi, E., Cannas, A., Ceravolo, R., Cicarelli, G., Ganglio, R.M., Lemolo, F., Manfredi, M., Meco, G., Nicoletti, A., Pederzoli, M., Petrone, A., Pisani, A., Pontieri, F.E., Quatrale, R., Remat, S., Scala, R., Volpe, G., Zappulla, S., Bentivoglio, A.R., Stocchi, F., Trianni, G. and Dotto, P.D. (2009) The PRIAMO Study: A Multicenter Assessment of Nonmotor Symptoms and Their Impact on Quality of Life in Parkinson's Disease. Movement Disorders, 24, 1619-1641. http://dx.doi.org/10.1002/mds.22643

[7] Havlikova, E., Rosenberger, J., Nagyova, I., Middel, B., Dubayova, T., Gdovinova, Z., Van Dijk, J.P. and Groothoff, J.W. (2008) Clinical and Psychosocial Factors Associated with Fatigue in Patients with Parkinson's Disease. Parkinsonism \& Related Disorders, 14, 187-192. http://dx.doi.org/10.1016/j.parkreldis.2007.07.017

[8] Chaudhuri, A., Condon, B.R., Gow, J.W., Brennan, D. and Hadley, D.M. (2003) Proton Magnetic Resonance Spectroscopy of Basal Ganglia in Chronic Fatigue Syndrome. NeuroReport, 14, 225-228. http://dx.doi.org/10.1097/00001756-200302100-00013

[9] Chaudhuri, A. and Behan, P.O. (2000) Fatigue and Basal Ganglia. Journal of the Neurological Sciences, 179, 34-42. http://dx.doi.org/10.1016/S0022-510X(00)00411-1

[10] Pavese, N., Metta, V., Bose, S., Chaudhuri, K.R. and Brooks, D.J. (2010) Fatigue in Parkinson’s Disease Is Linked to Striatal and Limbic Serotonergic Dysfunction. Brain, 133, 3434-3443. http://dx.doi.org/10.1093/brain/awq268

[11] Bryant, M.S., Rintala, D.H., Hou, J.G., Rivas, S.P., Fernandez, A.L., Lai, E.C. and Protas, E.J. (2012) The Relation of Falls to Fatigue, Depression and Daytime Sleepiness in Parkinson's Disease. European Neurology, 67, 326-330. http://dx.doi.org/10.1159/000335877

[12] Miwa, H. and Miwa, T. (2011) Fatigue in Patients with Parkinson’s Disease: Impact on Quality of Life. Internal Medicine, 50, 1553-1558. http://dx.doi.org/10.2169/internalmedicine.50.4954 
[13] Friedman, J.H. and Friedman, H. (1993) Fatigue in Parkinson’s Disease. Neurology, 43, 2016-2018. http://dx.doi.org/10.1212/WNL.43.10.2016

[14] Lau, Y.S., Patki, G., Das-Panja, K., Le, W.D. and Ahmad, S.O. (2011) Neuroprotective Effects and Mechanisms of Exercise in a Chronic Mouse Model of Parkinson's Disease with Moderate Neurodegeneration. European Journal of Neuroscience, 33, 1264-1274. http://dx.doi.org/10.1111/j.1460-9568.2011.07626.x

[15] Tajiri, N., Yasuhara, T., Shingo, T., Kondo, A., Yuan, W., Kadota, T., Wang, F., Baba, T., Tayra, J., Morimoto, T., Jing, M., Kikuchi, Y., Kuramoto, S., Agari, T., Miyoshi, Y., Fujino, H., Obata, F., Takeda, I., Furuta, T. and Date, I. (2010) Exercise Exerts Neuroprotective Effects on Parkinson’s Disease Model of Rats. Brain Research, 1310, 200-207. http://dx.doi.org/10.1016/j.brainres.2009.10.075

[16] Salmon, P. (2001) Effects of Physical Exercise on Anxiety, Depression, and Sensitivity to Stress: A Unifying Theory. Clinical Psychology Review, 21, 33-61. http://dx.doi.org/10.1016/S0272-7358(99)00032-X

[17] Wilson, W.M. and Marsden, C.A. (1996) In Vivo Measurement of Extracellular Serotonin in the Ventral Hippocampus during Treadmill Running. Behavioural Pharmacology, 7, 101-104. http://dx.doi.org/10.1097/00008877-199601000-00011

[18] Hoff, J.I., Van Hilten, J.J., Middelkoop, H.A.M. and Roos, R.A.C. (1997) Fatigue in Parkinson’s Disease Is Not Associated with Reduced Physical Activity. Parkinsonism Related Disorders, 3, 51-54.

[19] Elbers, R., Van Wegen, E.E., Rochester, L., Hetherington, V., Nieuwboer, A., Willems, A.M., Jones, D. and Kwakkel, G. (2009) Is Impact of Fatigue an Independent Factor Associated with Physical Activity in Patients with Idiopathic Parkinson's Disease? Movement Disorders, 24, 1512-1518. http://dx.doi.org/10.1002/mds.22664

[20] Hughes, A.J., Daniel, S.E., Kilford, L. and Lees, A.J. (1992) Accuracy of Clinical Diagnosis of Idiopathic Parkinson's Disease: A Clinico-Pathological Study of 100 Cases. Journal of Neurology, Neurosurgery Psychiatry, 55, 181-184. http://dx.doi.org/10.1136/jnnp.55.3.181

[21] Hoehn, M.M. and Yahr, M.D. (1967) Parkinsonism: Onset, Progression and Mortality. Neurology, 17, 573-581. http://dx.doi.org/10.1212/WNL.17.5.427

[22] Schenkman, M.L., Clark, K., Xie, T., Kuchibhatla, M., Shinberg, M. and Ray, L. (2001) Spinal Movement and Performance of Standing Reach Task in Participants with and without Parkinson's Disease. Physical Therapy, 81, 14001411.

[23] Fahn, S., Elton, R. and Members of the UPDRS Development Committee (1987) The Unified Parkinson's Disease Rating Scale. In: Fahn, S., Marsden, C.D., Calne, D.B. and Goldstein, M., Eds., Recent Developments in Parkinson's Disease, Vol. 2, McMellam Health Care Information, Florham Park, 153-163.

[24] Brucki, S.M.D., Nitrini, R., Caramelli, P., Bertolucci, P.H.F. and Okamoto, I.H. (2003) Sugestões para o uso do mini-exame do estado mental no Brasil. Arquivos de Neuro-Psiquiatria, 61, 777-781. http://dx.doi.org/10.1590/S0004-282X2003000500014

[25] Voorrips, L.E., Ravelli, A.C., Dongelmans, P.C., Deurenberg, P. and Van Staveren, W.A. (1991) A Physical Activity Questionnaire for the Elderly. Medicine Science in Sports Exercise, 23, 974-979. http://dx.doi.org/10.1249/00005768-199108000-00015

[26] Bink, B., Bonjer, F.H. and Van Der Sluys, H. (1966) Assessment of the Energy Expenditure by Indirect Time and Motion Study. In: Edang, K. and Andersen, K.L., Eds., Physical Activity in Health and Disease, Proceedings of the Bertoslös Symposium, Oslo University, Oslo, 207-214.

[27] Nascimento, C.M.C., Gobbi, S., Hirayama, M.S. and Brazão, M.C. (2008) Nível de atividade física e as principais barreiras percebidas por idosos de Rio Claro. Revista da Educação Física/UEM, 19, 109-118.

[28] Smets, E.M.A., Garssen, B., Bonke, B. and De Haes, J.C. (1995) The Multidimensional Fatigue Inventory (MFI) Psychometric Qualities of an Instrument to Assess Fatigue. Journal of Psychiatric Research, 39, 315-325.

[29] Friedman, J.H., Alves, G., Hagell, P., Marinus, J., Marsh, L., Martinez-Martin, P., Goetz, C.G., Poewe, W., Rascol, O., Sampaio, C., Stebbins, G. and Schrag, A. (2010) Fatigue Rating Scales Critique and Recommendations by the Movement Disorders Society Task Force on Rating Scales for Parkinson Disease. Movement Disorders, 25, 805-822. http://dx.doi.org/10.1002/mds.22989

[30] Rochester, L., Hetherington, V., Jones, D., Nieuwboer, A., Willems, A.M., Kwakkel, G. and Van Wegen, E. (2004) Attending to the Task: Interference Effects of Functional Tasks on Walking in Parkinson's Disease and the Roles of Cognition, Depression, Fatigue and Balance. Archives of Physical Medicine and Rehabilitation, 85, 1578-1585. http://dx.doi.org/10.1016/j.apmr.2004.01.025

[31] Hirsch, M.A. and Farley, B.G. (2009) Exercise and Neuroplasticity in Persons Living with Parkinson’s Disease. European Journal of Physical and Rehabilitation Medicine, 45, 215-229. 
Scientific Research Publishing (SCIRP) is one of the largest Open Access journal publishers. It is currently publishing more than 200 open access, online, peer-reviewed journals covering a wide range of academic disciplines. SCIRP serves the worldwide academic communities and contributes to the progress and application of science with its publication.

Other selected journals from SCIRP are listed as below. Submit your manuscript to us via either submit@scirp.org or Online Submission Portal.
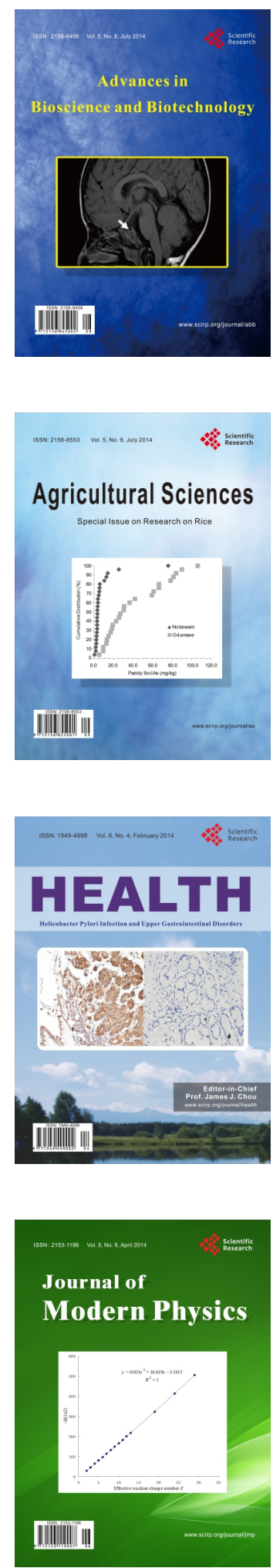
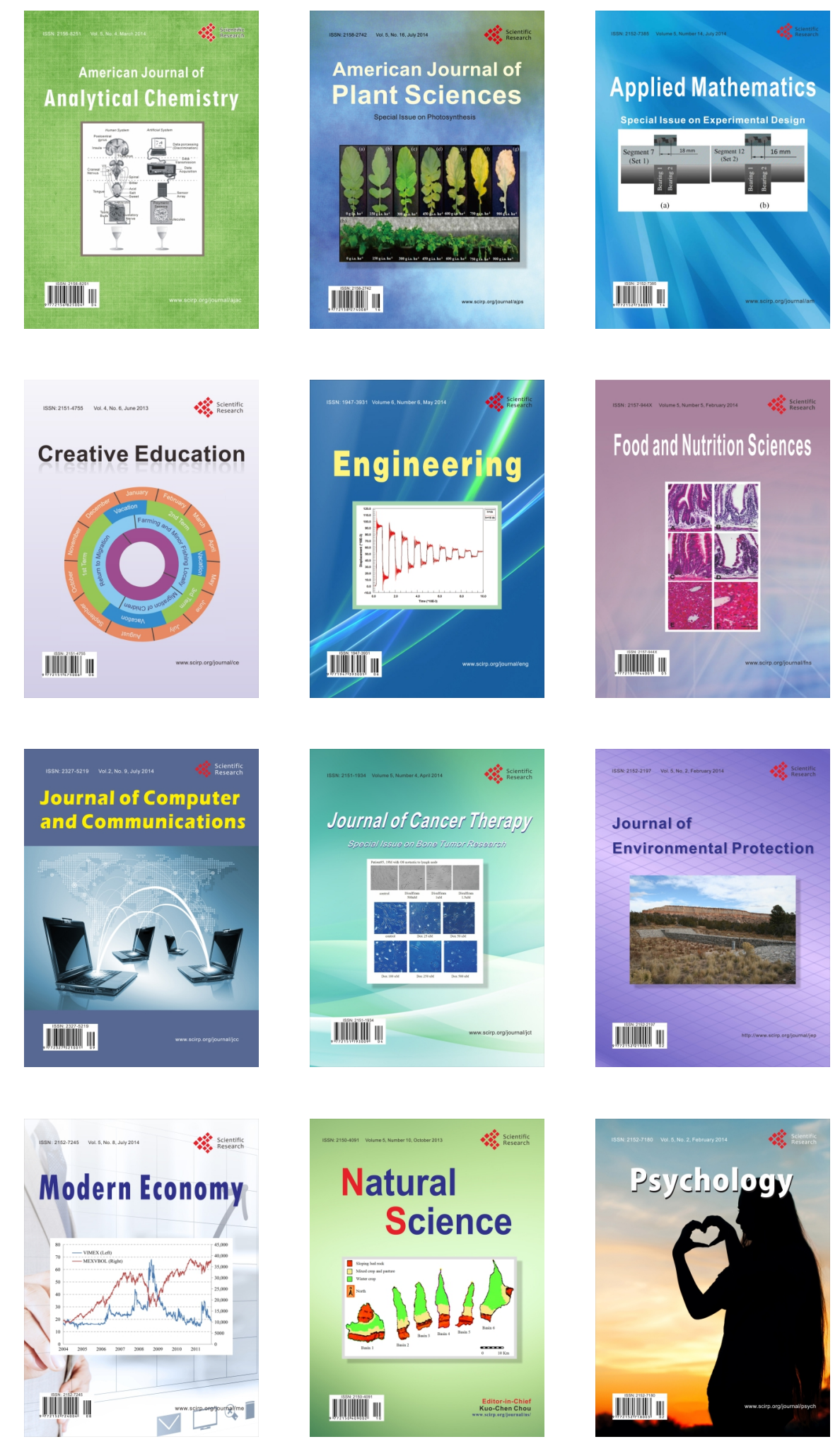